\title{
Numerical analysis of CMAS penetration induced interfacial delamination of transversely isotropic ceramic coat in thermal barrier coating system
}$$
\text { Luochuan } \mathrm{Su}^{1} \text {, Xi Chen }{ }^{2,3} \text {, T. J. Wang }{ }^{1, *}
$$ \\ ${ }^{1}$ State Key Laboratory for Strength and Vibration of Mechanical Structures, Department \\ of Engineering Mechanics, School of Aerospace Engineering, Xi' an Jiaotong University, \\ Xi'an 710049, China \\ ${ }^{2}$ International Center for Applied Mechanics, State Key Laboratory for Strength and \\ Vibration of Mechanical Structures, Xi'an Jiaotong University, Xi' an 710049, China \\ ${ }^{3}$ Department of Earth and Environmental Engineering, Columbia University, New York, \\ NY 10027, USA
}

\begin{abstract}
During the high-temperature operation of the electron beam physical vapor deposited (EB-PVD) thermal barrier coating system (TBCs), the environmental calcium-magnesium-alumina-silicate (CMAS) deposition would penetrate into the gaps between the columnar microstructure of top-coat. This penetration affects the mechanical behavior of coating and then induces the interfacial delamination of the coating from the substrate. In this paper, a physical model incorporating the CMAS penetration and the columnar microstructure of EB-PVD ceramic top-coat $\left(\mathrm{Y}_{2} \mathrm{O}_{3}-\right.$ Stabilized $\mathrm{ZrO}_{2}$, YSZ) is developed. Firstly, continuum analysis is carried out to investigate CMAS induced interfacial delamination in TBCs, in which the ceramic top-coat is simplified as a transversely isotropic material. Theoretical analysis indicates that CMAS penetration primarily affects the overall in-plane modulus of the top-coat. It is also shown that the
\end{abstract}

\footnotetext{
${ }^{*}$ Corresponding author, Postal address: No.28, West Xianning Road, Xi'an 710049, China

Tel: +86 29 82663318, Email: wangtj@mail.xjtu.edu.cn
} 
in-plane modulus of the top-coat is the most critical parameter determining the energy release rate and mode mixity. Moreover, the effect of columnar microstructure of top-coat on the interfacial delamination is analyzed. The results demonstrate that the increase of both CMAS modulus and penetration thickness can greatly promote the energy release rate for driving the interfacial delamination. The mechanism of CMAS induced interfacial delamination is that the infiltration of CMAS into columnar gaps increases the overall effective in-plane modulus of the top-coat, thereby facilitating delamination of the coat.

\section{Keywords}

Interfacial delamination; Thermal barrier coating; Transversely isotropic; CMAS penetration

\section{Introduction}

Thermal barrier coating system (TBCs) is widely used in gas turbines or aircraft engines [1-3]. During the high-temperature operation, channel cracks may initiate from the top-coat surface in TBCs and then develop into delamination at the interface [4-6], which imposes significant challenges to the durability of TBCs. In the last decades, the film/substrate model has been adopted to investigate the channel cracking and interfacial delamination in TBCs. In practice, when a channel crack reaches the interface of film/substrate, it either propagates into the substrate or bifurcates along the interface causing delamination, depending on the fracture toughness of substrate and interface [7]. In this work, we focus on the latter because of its practical importance in TBCs.

A fundamental work carried out by Hutchinson and Suo [8] indicated that for an 
elastic film/substrate system, the driving force for the steady-state growth of channel cracking $v s$ interfacial delamination is affected by the elastic constants, load conditions and fracture toughness of the film and interface. The effects of plastic deformation and viscoelastic deformation in the substrate on the driving force of channel cracking were analyzed by Ambrico et al. [9] and Huang et al. [10], respectively. Mei et al. [11] explored the influence of interfacial delamination on the growth of channel cracking and concluded that the delamination can significantly increase the driving force of channel cracking. A numerical process by Fan et al. [12] showed that introducing the periodic surface cracks can decrease the driving force of interfacial fracture. Recently, Chai and Fox [13] experimentally investigated the actual evolution process of interfacial delamination originated from channel cracks in thin-film coatings. In the aforementioned studies, the films or coatings were assumed to be isotropic. However, in some applications of thin-films or coatings, including the electron beam physical vapor deposited (EB-PVD) TBCs (Fig. 1) [14-17], the coatings exhibit transversely isotropic property and can no longer be treated as isotropic. This motivates the present work to investigate the interfacial delamination of transversely isotropic ceramic coat in TBCs.

Fig. 1(b) [18] presents a typical microstructure of EB-PVD coating, in which the ceramic top-coat layer $\left(\mathrm{Y}_{2} \mathrm{O}_{3}\right.$-Stabilized $\left.\mathrm{ZrO}_{2}, \mathrm{YSZ}\right)$ exhibits a columnar structure perpendicular to the interface. This special columnar microstructure with intercolumnar gaps results in completely different mechanical properties in the vertical (2-axis) and horizontal (1-axis) directions and the top-coat exhibits transversely isotropic properties [19-22]. As a matter of fact, the existence of intercolumnar gaps can help to provide strain 
tolerance and reduce thermal conductivity, necessary for high temperature application. Nevertheless, the environmental calcium-magnesium-alumina-silicate (CMAS) deposition adheres to top-coat surface and infiltrates the columnar gaps in the molten phase upon thermal exposure $[4,23-25]$. The penetration of CMAS deposition not only changes the mechanical properties of the top-coat, but also drives the interfacial delamination $[4,26]$. Therefore, a better understanding of the effects of transversely isotropic coating and CMAS penetration on interfacial delamination would improve the elucidation of the failure mechanism of EB-PVD TBCs.

In this paper, a physical model incorporating the columnar microstructure of EB-PVD ceramic coat and the CMAS penetration was developed. Firstly, a continuum analysis was carried out to investigate the interfacial delamination of the transversely isotropic ceramic coat on the substrate, where the roles of critical material parameters were discussed. Then, using the microstructure computational model, the effects of CMAS penetration on interfacial delamination were explored. Based on aforementioned analyses, the mechanism of CMAS penetration induced interfacial delamination was deduced, which may shed light on the mechanical integrity of EB-PVD TBCs.

\section{Statement of the problem}

\subsection{Observations on delamination with CMAS penetration}

As a typical failure mode of TBCs under high-temperature environment, the chemical CMAS deposits induced interfacial delamination has been widely observed in experiments [23-25, 27, 28]. Usually, the CMAS compositions adhere at the surface of top-coat firstly.

When the environmental temperature exceeds the melting point of CMAS, 
$T_{m}^{c m a s} \approx 1240^{\circ} \mathrm{C}$, which varies considerably depending on the CMAS composition [26, 29-31], the deposition would change into the molten status. As a result, the excellent wetting characteristic of CMAS enables it to penetrate into the gaps between YSZ columns. Then, upon the cooling stage, the composition solidifies into a stiff domain [23]. They would change the mechanical properties of the top-coat layer, and further induce interfacial delamination if a channel crack or vertical separation exists [26].

Typical observations of the interfacial delamination of top-coat in EB-PVD coating system with CMAS penetration are presented in Fig. 2. Fig. 2(a) shows the micrograph of the cross section for a TBCs sample with CMAS penetration after a long time exposure at the high-temperature environment [25], where the CMAS deposits infiltrate into the gaps between YSZ columns, making the porous top-coat layer dense, especially near the top-coat surface. At the root of a channel crack or vertical separation, the interfacial delamination can be observed. It should be pointed out that, in some regions of Fig. 2(b) $[23,26]$, delamination occurs within the top-coat and the YSZ columns only be removed partly. In addition, some new TBC materials with CMAS penetration resistance have been reported recently and observations have shown that, in these cases, the CMAS is mitigated and the delamination also occur within the top-coat layer [32-34]. The possibility of delamination within the top-coat is that there is only partial CMAS infiltration. In this work, we focus on the interfacial delamination initiating from the end of a channel crack or vertical separation, since it can remove the whole top-coat layer and cause the ultimate failure of TBCs, like the spallation shown in Fig. 2(b), where the interface exposures to environment. 
A schematic of CMAS induced interfacial delamination is illustrated in Fig. 2(c). Initially, the gaps between YSZ columns are filled with high-porosity feathery microstructure (Fig. 1(b)). Upon high temperature exposure, some of the porosity gaps would be infiltrated by the molten CMAS deposits and the infiltration depth is determined by the temperature distribution within the top-coat [23], which means that CMAS penetration thickness varies in different coating systems or operation conditions. Also, the modulus of CMAS varies with the proportion of chemical compositions [35]. Usually, the CMAS penetration can greatly change the mechanical properties of top-coat. As a result, interfacial delamination is likely to be induced from the root of a channel crack or vertical separation (Fig. 2(c)).

\subsection{Physical model}

Based on the aforementioned observations, a physical model incorporating CMAS penetration was developed, as shown in Fig. 3, where both YSZ columns and the gaps were modeled to present the transversely isotropic property of the whole top-coat, and all columns were assumed to be straight and parallel. Note that the material within one column or gap was considered as isotropic. $D$ and $d$ are the width of columns and gaps, respectively. The penetration thickness of CMAS into the gaps, $h_{C M A S}$, varied between 0 and the top-coat thickness $h_{Y S Z}$. It should be pointed out that besides the penetration parts there is a thin CMAS layer adhereing at the surface of top-coat [23, 27], which was not considered in the model. In addition, for EB-PVD TBCs, interface between the top-coat and the bond-coat is relatively flat and the thermally grown oxide (TGO) layer is smooth without significant undulation [3]. So, TGO was also neglected and the impact of this 
assumption would be discussed later. The interfacial crack in the model initiates from the free edge of a channel crack or vertical separation.

For the columnar model in Fig. 3, the macroscopic equivalent in-plane (1-axis) modulus $E_{1}^{e q}$ and out-of-plane (2-axis) modulus $E_{2}^{e q}$ of the top-coat could be derived on the basis of mixture rule in micromechanics $[36,37]$. As a result, $E_{1}^{e q}$ and $E_{2}^{e q}$ could be respectively expressed as (see Appendix A for detail),

$$
E_{1}^{e q}=\frac{(D+d) E_{Y S Z}}{h_{Y S Z}}\left[\frac{E_{C M A S} h_{C M A S}}{D E_{C M A S}+d E_{Y S Z}}+\frac{E_{G A P}\left(h_{Y S Z}-h_{C M A S}\right)}{D E_{G A P}+d E_{Y S Z}}\right]
$$

and

$$
E_{2}^{e q}=\frac{h_{Y S Z}\left(D E_{Y S Z}+d E_{C M A S}\right)\left(D E_{Y S Z}+d E_{G A P}\right)}{(D+d)\left(D h_{Y S Z} E_{Y S Z}+d h_{Y S Z} E_{C M A S}-d h_{C M A S} E_{C M A S}+d h_{C M A S} E_{G A P}\right)}
$$

where $E_{Y S Z}$ and $E_{C M A S}$ are the Young's modulus of YSZ columns and CMAS deposits, respectively, and $E_{G A P}$ represents the modulus of the high-porosity feathery microstructure in the gaps. The microstructure determines that the macroscopic equivalent modulus along 3-axis $\left(E_{3}^{e q}\right)$ is equal to $E_{1}^{e q}$. If $h_{C M A S}=h_{Y S Z}$ and $E_{C M A S}=E_{Y S Z}$, Eqs. (1) and (2) can be rewritten as $E_{1}^{e q}=E_{2}^{e q}=E_{Y S Z}$, which means that the top-coat is isotropic. Note that since there is almost no difference between the Poisson's ratio of YSZ columns and CMAS deposits [26], the effect of Poisson's ratio was not emphasized in this work.

The variations of the equivalent in-plane modulus $E_{1}^{e q}$ and out-of-plane modulus $E_{2}^{e q}$ with the increase of CMAS modulus are plotted in Fig. 4. It is seen that the effect of CMAS penetration mainly affects the in-plane modulus $E_{1}^{e q}$. For the case of $h_{C M A S}=h_{Y S Z}$, when $E_{C M A S}$ increases from $5 \mathrm{GPa}$ to $120 \mathrm{GPa}, E_{1}^{e q}$ can increase up to 3 times. Similar trend can also be investigated for other cases. Therefore, the penetration of CMAS can 
result in a noticeable increase on the macroscopic in-plane modulus of the top-coat.

Inspired by above observations and analyses, we took the ceramic top-coat as a transversely isotropic material. Let the 1-3 plane be the plane with isotropy, and then the stress-strain relation for the transversely isotropic top-coat could be expressed as,

$$
\left\{\begin{array}{l}
\varepsilon_{11} \\
\varepsilon_{22} \\
\varepsilon_{33} \\
\gamma_{12} \\
\gamma_{13} \\
\gamma_{23}
\end{array}\right\}=\left[\begin{array}{cccccc}
1 / E_{1} & -v_{21} / E_{2} & -v_{31} / E_{3} & 0 & 0 & 0 \\
-v_{12} / E_{1} & 1 / E_{2} & -v_{32} / E_{3} & 0 & 0 & 0 \\
-v_{13} / E_{1} & -v_{23} / E_{2} & 1 / E_{3} & 0 & 0 & 0 \\
0 & 0 & 0 & 1 / \mu_{12} & 0 & 0 \\
0 & 0 & 0 & 0 & 1 / \mu_{13} & 0 \\
0 & 0 & 0 & 0 & 0 & 1 / \mu_{23}
\end{array}\right]\left\{\begin{array}{l}
\sigma_{11} \\
\sigma_{22} \\
\sigma_{33} \\
\sigma_{12} \\
\sigma_{13} \\
\sigma_{23}
\end{array}\right\}
$$

where $E_{1}=E_{3}, v_{13}=v_{31}, v_{12}=v_{32}, v_{21}=v_{23}$, and the shear modulus $\mu_{12}=\mu_{23}$. The relation of $v_{12}$ and $v_{21}$ is [19]

$$
\frac{v_{12}}{E_{1}}=\frac{v_{21}}{E_{2}}
$$

In the isotropic 1-3 plane, the elastic parameters are related by

$$
\mu_{13}=\frac{E_{1}}{2\left(1+v_{13}\right)} .
$$

It is seen that there are five independent elastic constants in Eq. (3), i.e. $E_{1}, E_{2}, v_{12}$, $\nu_{13}$ and $\mu_{12}$. In order to further simplify the problem, we adopted the assumption for EB-PVD coating [19],

$$
v_{21}=v_{13}, \quad \mu_{12}=\left(\frac{E_{2}}{E_{1}}\right) \mu_{13} .
$$

Therefore, only three parameters $\left(E_{1}, E_{2}\right.$ and $\left.v_{13}\right)$ need to be specified in the analysis. In the following sections, a continuum analysis would be carried out firstly to investigate the effect of CMAS penetration on the overall responses of interfacial delamination in TBCs, where the ceramic top-coat was simplified as a transversely 
isotropic material in a film/substrate system and the roles of in-plane and out-of-plane moduli were explored. Moreover, with the consideration of columnar microstructure, the effect of microstructure of CMAS penetration on delamination would also be analyzed.

\section{Continuum analysis}

\subsection{Interfacial delamination in film/substrate system}

Herein, we firstly simplified the TBCs as a transversely isotropic film/substrate system and a continuum analysis of the interfacial delamination in the system would be carried out. Consider an interfacial crack initiating from the root of a channel crack (gap) with the length, $2 a$, as shown in Fig. 5(a), where the thin film is under tensile stress. Based on the previous works $[8,11,12]$, if the film and substrate are isotropic, the energy release rate $G$ for a steady-state interfacial crack in Fig. 5 could be expressed as

$$
G=g\left(\frac{a}{h_{f}}, \alpha, \beta, \frac{w}{h_{f}}\right) \frac{\sigma_{f}^{2} h_{f}}{\bar{E}_{f}},
$$

where $h_{f}$ is the film thickness, $\sigma_{f}$ is the tensile stress in the film, and $\bar{E}_{f}=E_{f} /\left(1-v_{f}^{2}\right)$ with $E_{f}$ and $v_{f}$ being the Young's modulus and Poisson's ratio of the film, respectively. $w$ is the channel crack spacing presenting the effect of adjacent channel cracks [12]. As $w \rightarrow \infty$, the problem reduces to a single crack problem and $w$ will have no effect on the energy release rate $G$. The Dundurs' parameters $\alpha$ and $\beta$ represent the dependence of $G$ on the elastic misfit between the film and the substrate [8, 11],

$$
\alpha=\frac{\bar{E}_{f}-\bar{E}_{s}}{\bar{E}_{f}+\bar{E}_{s}}
$$




$$
\beta=\frac{\bar{E}_{f}\left(v_{f}-1\right)\left(2 v_{s}-1\right)-\bar{E}_{s}\left(v_{s}-1\right)\left(2 v_{f}-1\right)}{2\left(v_{f}-1\right)\left(v_{s}-1\right)\left(\bar{E}_{f}+\bar{E}_{s}\right)}
$$

It could be concluded from Eqs. (7) to (9) that if the materials in the film/substrate system are transversely isotropic, the Dundurs' parameters $\alpha$ and $\beta$ should be redefined. However, to the authors' knowledge, it is very difficult to obtain a precise new definition for both $\alpha$ and $\beta$. For the current work, there are only three independent transversely isotropic elastic parameters, $E_{1}, E_{2}$ and $v_{13}$. Therefore, we focused primarily on the roles of these transversely isotropic parameters on the energy release rate of interfacial crack, especially the ratio of the in-plane modulus $E_{1}$ to out-of-plane modulus $E_{2}$.

\subsection{Numerical calculations}

The energy release rate was calculated by using a two-dimensional plane strain model, as shown in Fig. 5(b), where a transversely isotropic film with thickness $h_{f}=100 \mu m$ was bonded to an infinite substrate. Due to the symmetry of the problem, only half of the system was modeled. To circumvent the influence from other channel cracks, the crack spacing $w=100 h_{f}$ was adopted [12] with the periodic boundary condition imposed at the right side. The film and the substrate were considered to be linear elastic. The in-plane Poisson's ratio, $v_{13}^{f}$, was taken to be 0.1 in all calculations [19]. To explore the roles of in-plane modulus $E_{1}^{f}$ and out-of-plane modulus $E_{2}^{f}, E_{1}^{f}$ was varied between 20GPa and 200GPa, and $E_{2}^{f}$ was varied between 40GPa and 200GPa. If not mentioned otherwise, the substrate was treated as isotropic with Poisson's ratio $v_{s}=0.3$ and Young's modulus $E_{s}=210 G P a$.

All calculations were carried out by finite element method using the commercial code 
ABAQUS. A constant tensile strain was applied to the right side of the thin film, which in practice can be induced by thermal misfit in TBCs. More than 17,000 four-node plane strain elements (CPE4R) were used in the model. As shown in Fig. 5(c), a very fine mesh was used near the crack tip and the quarter-point elements were employed to capture the singularity. The mesh sensitivity was checked before calculations. Herein, J-integral was adopted to calculate the energy release rate [11, 38].

\subsection{The energy release rate}

When the maximum value of energy release rate $G$ exceeds the interface toughness, the interfacial crack begins to extend. Since the interface toughness is a function of mode mixity $\varphi$ [8], which is a relative amount of mode-II to mode-I fracture ahead of crack-tip, the extension of delamination crack is determined by both the energy release rate and mode mixity. The trends of energy release rate and mode mixity with interfacial crack length are presented in Fig. 6. Herein, we firstly treated the out-of-plane modulus as a constant, i.e. $E_{2}^{f}=150 G P a$ (whose role would be discussed later), and the results for three typical in-plane moduli were given. (1) $E_{1}^{f}=50 G P a\left(E_{1}^{f}<E_{2}^{f}\right)$, i.e. the material stiffness in horizontal direction (1-axis) is smaller than that in vertical direction (2-axis), (2) $E_{1}^{f}=150 G P a\left(E_{1}^{f}=E_{2}^{f}\right)$, i.e. the film is isotropic, and (3) $E_{1}^{f}=200 G P a\left(E_{1}^{f}>E_{2}^{f}\right)$, i.e. the material stiffness in horizontal direction is larger than that in vertical direction. In addition, all the results of energy release rate in this section were normalized by a reference value $G_{0} . G_{0}$ was obtained in the case of $E_{1}^{f}=E_{2}^{f}$ (isotropic) and $a=5 h_{f}$. It is clear that regardless of the anisotropy ratio $E_{1}^{f} / E_{2}^{f}$, as long as the crack is short, both the energy release rate and mode mixity monotonically change with the increase of 
crack length. However, when the crack is relative long, they approach a constant value and the crack reaches a steady state. These trends are the same as that of the isotropic film [11, $12]$.

\subsection{Effects of in-plane and out-of -plane moduli of film ( $E_{1}^{f}$ and $\left.E_{2}^{f}\right)$}

As the statement in section 2, the main focus of this section is to elucidate the effects of in-plane modulus $E_{1}^{f}$ and out-of-plane modulus $E_{2}^{f}$ on the interfacial delamination. Then, the roles of $E_{1}^{f}$ and $E_{2}^{f}$ on the energy release rate and mode mixity would be discussed respectively.

The variations of normalized energy release rate and mode mixity are plotted in Fig. 7 as the functions of in-plane modulus $E_{1}^{f}$. Here, the results for six different crack lengths (short crack: $a=0.5 h_{f}$ and $a=1.0 h_{f}$, and long crack: $a=2 h_{f}, a=3 h_{f}, a=4 h_{f}$ and $a=5 h_{f}$ ) were given, and $E_{1}^{f}$ was varied in a practical range from 20GPa to 200GPa. It is seen that both the energy release rate and mode mixity increase significantly with the increase of $E_{1}^{f}$. For the case of $a=5 h_{f}$, the increase of energy release rate can be up to 10 times (Fig. 7(a)) and the mode mixity increases from $49^{\circ}$ to $57^{\circ}$ (Fig. 7(b)). This effect also can be observed for other cases. It indicates that the in-plane modulus of film would greatly affect the interfacial delamination.

The effect of out-of-plane modulus of the film $\left(E_{2}^{f}\right)$ on the energy release rate and mode mixity are depicted in Fig. 8 , where $E_{1}^{f}$ was treated as a constant and $E_{2}^{f}$ was varied from 40GPa to 200GPa. For the long crack, the energy release rate and mode mixity are insensitive to $E_{2}^{f}$, and vary only in a very small range. For the short crack $\left(a=0.5 h_{f}\right)$, the variation is much more obvious, which mainly results from the oscillation 
induced by boundary conditions when the crack is under an unstable state [11]. However, compared to the effect of $E_{1}^{f}$, the effect of $E_{2}^{f}$ is minor.

\subsection{Effects of substrate moduli ( $E_{1}^{s}$ and $\left.E_{2}^{s}\right)$}

In above discussions, the substrate was treated as the isotropic material. To understand the role of substrate properties, we further treated it as a transversely isotropic material. Similarly, the assumption of stress-strain relation for substrate is the same as that in section 2.2. Considering the practical application, the in-plane and out-of-plane moduli of the substrate $\left(E_{1}^{s}\right.$ and $E_{2}^{s}$ ) were allowed to vary between $80 \mathrm{GPa}$ and 240GPa. Fig. 9 presents the variations of energy release rate $G$ and mode mixity $\varphi$ with $E_{1}^{s}$ and $E_{2}^{s}$ for a steady-state interfacial crack $\left(a=5 h_{f}\right)$. Fig. 9(a) indicates that, for the same film modulus, no matter the film is transversely isotropic $\left(E_{1}^{f}=50 \mathrm{GPa}\right.$ or $200 \mathrm{GPa}$ ) or isotropic ( $E_{1}^{f}=150 \mathrm{GPa}$ ), the energy release rate is completely insensitive to $E_{1}^{s}$ and $E_{2}^{s}$. It changes only when varying the in-plane modulus of film $E_{1}^{f}$. The mode mixity $\varphi$ is also insensitive to $E_{1}^{s}$, but it shows a tiny change with the increase of $E_{2}^{s}$. In practice, this change of mode mixity could not result in a noticeable impact on the interface fracture.

Therefore, it could be concluded that for the interfacial delamination in film/substrate system, the in-plane modulus of film plays a dominant role in the driving force and mode mixity. To verify the analysis in the continuum framework and obtain the mechanism of CMAS penetration induced interfacial delamination, analysis incorporating the columnar microstructure would be carried out in next section.

\section{Analysis incorporating columnar microstructure}


In this section, the interfacial delamination would be further investigated by using a columnar microstructure model with CMAS penetration, and the effects of microstructure on interfacial delamination would be emphasized. The geometry of computational model is shown in Fig. 3. In the numerical calculations, the thicknesses for YSZ top-coat, bond-coat and substrate are $h_{Y S Z}=100 \mu m, h_{B C}=100 \mu m$ and $h_{\text {sub }}=2000 \mu m$, respectively. 200 columns were included in the model and the width of each column is $D=9 \mu m$. To obtain a $10 \%$ porosity of top-coat, which is a common value in most EB-PVD thermal barrier coating systems [39, 40], the gap width $d=1 \mu m$ was taken in most calculations. All the materials in the model possessed linear elastic behavior and the material parameters are list in Table 1, where the Young's modulus for CMAS deposits was varied in calculations. Before CMAS penetration, the gaps were considered to be filled with high-porosity feathery microstructure $[2,26]$, therefore, the Young's modulus of the materials in the gaps without CMAS penetration was taken to be 5GPa [26].

Fig. 10 shows the effect of CMAS modulus on the normalized energy release rate $G$, where the reference value $G_{*}$ was obtained in the case of $h_{C M A S}=h_{Y S Z}, E_{C M A S}=E_{Y S Z}$ (isotropic) and $a=50(d+D)$. The results obtained by the aforementioned continuum model are also presented, in which the equivalent moduli were predicted by Eqs. (1) and (2) using the microstructure parameters of columnar model. It is seen that the energy release rate exhibits an increase with the increase of CMAS modulus. When the value of CMAS modulus is relative small (about 5-60GPa herein), its increase can induce a rapid growth of energy release rate, which is consistent with its effect on the macroscopic in-plane modulus of top-coat (Fig. 4). Note that when $h_{C M A S}=h_{Y S Z}$, the results obtained 
from the present columnar model agree well with that of continuum analysis, no matter the crack is short $\left(a=5(d+D)=0.5 h_{Y S Z}\right)$ or long $\left(a=50(d+D)=5 h_{Y S Z}\right)$. However, if the gaps are not fully filled with CMAS, i.e., $h_{C M A S}=0.5 h_{Y S Z}$ or $h_{C M A S}=0.3 h_{Y S Z}$, there is a small difference between the two models owing to the bending effect of YSZ columns [26]. In practice, the mechanical properties of top-coat between the parts filled with CMAS and without CMAS are different. As a result, when the TBCs is subjected to thermal misfit, bending deformation of the YSZ columns would occur. The absence of bending effect in the continuum analysis results in the difference from columnar model, especially for smaller column width as exemplified in Fig. 11, where $D+d$ is taken to be a constant and $h_{C M A S}=0.5 h_{Y S Z}$. Herein, we defined a relative change of energy release rate, $\delta=\left|G_{c o l}-G_{e q}\right| / G_{c o l} \times 100 \%$, in which $G_{c o l}$ and $G_{e q}$ are the energy release rate obtained from the columnar model and continuum model, respectively. It is seen from Fig. 11 that thinner column width ( $D=9.0 \mu \mathrm{m}$ or $D=8.5 \mu \mathrm{m}$ ) shows a larger $\delta$, which indicates the effect of columns bending and supports our explanation for the difference between two models in Fig. 10. Nevertheless, in most cases, the continuum analysis can catch the general characteristics of CMAS penetration effect in columnar EB-PVD coating.

The combined effects of CMAS modulus and penetration thickness on the energy release rate are shown in Fig. 12. It is clear that the increase of CMAS modulus or penetration thickness can result in a noticeable growth of driving force for interfacial delamination. When both CMAS modulus and penetration thickness are varied simultaneously from their minimum $\left(E_{C M A S}=5 G P a\right.$ and $\left.h_{C M A S}=0\right)$ to the maximum ( $E_{C M A S}=120 G P a$ and $h_{C M A S}=h_{Y S Z}$ ), the energy release rate also reaches the maximum. 
This means that the strongest driving force for interfacial delamination would be gained when the gaps are fully filled with dense CMAS penetration, which is consistent with the trend of in-plane modulus in Fig. 4. Therefore, in essence, the penetration of CMAS increases the effective in-plane modulus of top-coat, and then results in a rapid growth of the driving force for interfacial delamination. Practically, CMAS penetration in YSZ top-coat is impeded by both the thermal insulation of ceramic coating and the internal cooling of substrate. Experimental investigation [23] has shown that there is a critical penetration thickness, $h_{C M A S}^{*}$, only above which the delamination occurs during the thermal shock. In order to consider all possible penetration cases, we varied $h_{\text {CMAS }}$ from 0 to the top-coat thickness $\left(h_{Y S Z}\right)$ in the model, and the results have shown that the driving force for delamination crack increases significantly with the increase of $h_{C M A S}$. It is easy to conclude that, when the driving force is large enough, i.e., $h_{C M A S}$ reaches the critical value, the interfacial delamination is likely to initiate and propagate. This is consistent with the experimental trend [23]. In addition, as the increase of CMAS penetration thickness, it can still build up sufficient elastic energy to cause crack initiation and propagation within the top-coat. In this work, we focused on the interfacial delamination.

Another interesting aspect for the mode mixity is shown in Fig. 13. When CMAS penetration thickness is large $\left(h_{C M A S}=h_{Y S Z}\right.$ or $\left.h_{C M A S}=0.8 h_{Y S Z}\right)$, the mode mixity also presents an increase with the increase of CMAS modulus, which is consistent with the prediction by continuum analysis in section 3.4. Conversely, when the penetration thickness is small $\left(h_{C M A S}=0.5 h_{Y S Z}\right.$ or $\left.h_{C M A S}=0.2 h_{Y S Z}\right)$, the mode mixity presents a decrease. Recall that when the gaps are partly filled with CMAS, the bending effect of 
YSZ columns would appear. As a result, the bending deformation would result in additional tensile stress at the interface and enhance the mode-I fracture, which would become more significant as the increase of CMAS modulus. It is clear from Fig.13 that the mode mixity is insensitive to the increase of CMAS modulus for the case of $h_{C M A S}=0.7 h_{Y S Z}$. Therefore, there might be a transition around $h_{C M A S}=0.7 h_{Y S Z}$, where the mode mixity is constant. However, it should be pointed out that the variations of mode mixity for all cases in Fig. 13 are within a fairly small range and this may not induce a noticeable impact on interface fracture.

It is expected that the interfacial delamination between top-coat and bond-coat does not only depend on CMAS penetration, but also TGO growth and interface undulation as well. In the present paper, we focused on the effect of CMAS penetration on the mechanical properties of EB-PVD top-coat and explored the role of top-coat on interfacial delamination. Thus, the impact of TGO layer was dismissed.

\section{Conclusions}

During the high-temperature operation of EB-PVD thermal barrier coating system, the environmental CMAS deposition would penetrate into the gaps between the YSZ columns of top-coat, and then affect the mechanical behavior of the coating. In this work, we developed a physical model incorporating the CMAS penetration and the columnar microstructure of YSZ top-coat. Then, numerical analysis has been carried out to investigate the effect of CMAS penetration on the overall responses of interfacial delamination. Theoretical prediction indicates that the CMAS penetration primarily affects the overall in-plane modulus of the top-coat. It is also shown that the in-plane modulus of 
top-coat plays a dominated role on the energy release rate and mode mixity for interfacial delamination. The increase of both CMAS modulus and penetration thickness can greatly promote the energy release rate for driving the interfacial crack. The mechanism of CMAS penetration induced interfacial delamination in EB-PVD coating is that the infiltration of CMAS deposits into gaps between YSZ columns increases the effective in-plane modulus of top-coat, thereby facilitating delamination. This also can be used to explain the delamination induced by top-coat sintering.

Acknowledgements. This work is supported by China 973 Program (2013CB035701) and NSFC (11321062 and 11172227). XC acknowledges additional support from NSFC (11172231 and 11372241), ARPA-E (DE-AR0000396) and AFOSR (FA9550-12-1-0159).

\section{Appendix A}

The mixture rule in micromechanics $[36,37]$ is employed to predict the overall in-plane (1-axis) and out-of-plane (2-axis) moduli of the top-coat. We divide the whole top-coat into two parts, as shown in Fig. A1, in which part A with CAMS and part B without CMAS. According the Reuss and Voigt estimates, the in-plane and out-of-plane moduli for part $\mathrm{A}\left(E_{1, A}^{e q}\right.$ and $\left.E_{2, A}^{e q}\right)$ can be expressed as

$$
\begin{aligned}
& E_{1, A}^{e q}=\frac{E_{C M A S} E_{Y S Z}}{E_{C M A S} V_{Y S Z}+E_{Y S Z} V_{C M A S}} \\
& E_{2, A}^{e q}=E_{Y S Z} V_{Y S Z}+E_{C M A S} V_{C M A S}
\end{aligned}
$$

where $V_{Y S Z}$ and $V_{C M A S}$ are the volume fractions of YSZ columns and CMAS penetration, respectively, which can be expressed by $V_{Y S Z}=D /(D+d)$ and $V_{C M A S}=d /(D+d)$. 
The moduli for part B have the same expressions as Eqs. (A1) and (A2),

$$
\begin{aligned}
& E_{1, B}^{e q}=\frac{E_{G A P} E_{Y S Z}}{E_{G A P} V_{Y S Z}+E_{Y S Z} V_{G A P}} \\
& E_{2, B}^{e q}=E_{Y S Z} V_{Y S Z}+E_{G A P} V_{G A P}
\end{aligned}
$$

where $V_{G A P}$ is the same as $V_{C M A S}$.

Similarly, we further treat the whole top-coat as a two-phase composite, i.e., part A is one phase and part B is another phase. Therefore, the equivalent in-plane and out-of-plane moduli for the top-coat ( $E_{1}^{e q}$ and $E_{2}^{e q}$ ) can be approximatively written as,

$$
\begin{aligned}
& E_{1}^{e q}=E_{1, A}^{e q} V_{A}+E_{1, B}^{e q} V_{B} \\
& E_{2}^{e q}=\frac{E_{2, A}^{e q} E_{2, B}^{e q}}{E_{2, A}^{e q} V_{B}+E_{2, B}^{e q} V_{A}}
\end{aligned}
$$

where $V_{A}=h_{C M A S} / h_{Y S Z}$ and $V_{B}=1-h_{C M A S} / h_{Y S Z}$.

Substituting Eqs. (A1)-(A4) to Eqs. (A5) and (A6), we have,

$$
\begin{aligned}
& E_{1}^{e q}=\frac{(D+d) E_{Y S Z}}{h_{Y S Z}}\left[\frac{E_{C M A S} h_{C M A S}}{D E_{C M A S}+d E_{Y S Z}}+\frac{E_{G A P}\left(h_{Y S Z}-h_{C M A S}\right)}{D E_{G A P}+d E_{Y S Z}}\right] \\
& E_{2}^{e q}=\frac{h_{Y S Z}\left(D E_{Y S Z}+d E_{C M A S}\right)\left(D E_{Y S Z}+d E_{G A P}\right)}{(D+d)\left(D h_{Y S Z} E_{Y S Z}+d h_{Y S Z} E_{C M A S}-d h_{C M A S} E_{C M A S}+d h_{C M A S} E_{G A P}\right)}
\end{aligned}
$$

\section{References}

[1] D.R. Clarke, M. Oechsner, N.P. Padture, Thermal-barrier coatings for more efficient gas-turbine engines, MRS Bull. 37 (2012) 891-898.

[2] A.G. Evans, D.R. Mumm, J.W. Hutchinson, G.H. Meier, F.S. Pettit, Mechanisms controlling the durability of thermal barrier coatings, Prog. Mater. Sci. 46 (2001) 505-553. [3] N.P. Padture, M. Gell, E.H. Jordan, Thermal barrier coatings for gas-turbine engine applications, Science. 296 (2002) 280-284.

[4] A.G. Evans, J.W. Hutchinson, The mechanics of coating delamination in thermal gradient, Surf. Coat. Technol. 201 (2007) 7905-7916. 
[5] A.G. Evans, M.Y. He, J.W. Hutchinson, Mechanics-based scaling laws for the durability of thermal barrier coatings, Prog. Mater. Sci. 46 (2001) 249-271.

[6] J.W. Hutchinson, A.G. Evans, On the delamination of thermal barrier coatings in a thermal gradient, Surf. Coat. Technol. 149 (2002) 179-184.

[7] T. Ye, Z. Suo, A.G. Evans, Thin film cracking and the roles of substrate and interface, Int. J. Solids. Struct. 29 (1992) 2639-2648.

[8] J.W. Hutchinson, Z.G. Suo, Mixed mode cracking in layered materials, Adv. Appl. Mech. 29 (1992) 63-191.

[9] J.M. Ambrico, M.R. Begley, The role of initial flaw size, elastic compliance and plasticity in channel cracking of thin films, Thin Solid Films. 419 (2002) 144-153.

[10] R. Huang, J.H. Prevost, Z. Suo, Loss of constraint on fracture in thin film structures due to creep, Acta Mater. 50 (2002) 4137-4148.

[11] H. Mei, Y. Pang, R. Huang, Influence of interfacial delamination on channel cracking of elastic thin films, Int. J. Fract. 148 (2007) 331-342.

[12] X.L Fan, R. Xu, W.X. Zhang, T.J. Wang, Effect of periodic surface cracks on the interfacial fracture of thermal barrier coating system, Appl. Surf. Sci. 258 (2012) 9816-9823.

[13] H. Chai, J. Fox, On delamination growth from channel cracks in thin-film coatings, Int. J. Solids. Struct. 49 (2012) 3142-3147.

[14] T. Strangman, D. Raybould, A. Jameel, W. Baker, Damage mechanisms, life prediction, and development of EB-PVD thermal barrier coatings for turbine airfoils, Surf. Coat. Technol. 202 (2007) 658-664.

[15] Y. Sohn, J. Kim, E. Jordan, M. Gell, Thermal cycling of EB-PVD/MCrAlY thermal barrier coatings: I. Microstructural development and spallation mechanisms, Surf. Coat. Technol. 146 (2001) 70-78.

[16] D.R. Mumm, A.G. Evans, I.T. Spitsberg, Characterization of a cyclic displacement instability for a thermally grown oxide in a thermal barrier system, Acta Mater. 49 (2001) 2329-2340.

[17] L. Su, W. Zhang, Y. Sun, T.J. Wang, Effect of TGO creep on the top-coat cracking induced by the cyclic displacement instability in thermal barrier coating system, Surf. Coat. 
Technol. 254 (2014) 410-417.

[18] V. Lughi, V.K. Tolpygo, D.R. Clarke, Microstructural aspects of the sintering of thermal barrier coatings, Mater. Sci. Eng. A. 368 (2004) 212-221.

[19] E.P. Busso, Z.Q. Qian, A mechanistic study of microcracking in transversely isotropic ceramic-metal systems, Acta Mater. 54 (2006) 325-338.

[20] B.K. Jang, H. Matsubara, Influence of porosity on hardness and Young's modulus of nanoporous EB-PVD TBCs by nanoindentation, Mater. Lett. 59 (2005) 3462-3466.

[21] E. Lugscheider, K. Bobzin, S. Bärwulf, A. Etzkorn, Mechanical properties of EB-PVD-thermal barrier coatings by nanoindentation, Surf. Coat. Technol. 138 (2001) 9-13.

[22] M. Peters, C. Leyens, U. Schulz, W.A. Kaysser, EB - PVD Thermal Barrier Coatings for Aeroengines and Gas Turbines, Adv. Eng. Mater. 3 (2001) 193-204.

[23] C. Mercer, S. Faulhaber, A.G. Evans, R. Darolia, A delamination mechanism for thermal barrier coatings subject to calcium-magnesium-alumino-silicate (CMAS) infiltration, Acta Mater. 53 (2005) 1029-1039.

[24] S. Krämer, J. Yang, C.G. Levi, Infiltration - Inhibiting Reaction of Gadolinium Zirconate Thermal Barrier Coatings with CMAS Melts, J. Amer. Ceram. Soc. 91 (2008) 576-583.

[25] H. Peng, L. Wang, L. Guo, W. Miao, H. Guo, S. Gong, Degradation of EB-PVD thermal barrier coatings caused by CMAS deposits, Prog. Nat. Sci: Mater. Int. 22 (2012) 461-467.

[26] X. Chen, Calcium-magnesium-alumina-silicate (CMAS) delamination mechanisms in EB-PVD thermal barrier coatings, Surf. Coat. Technol. 200 (2006) 3418-3427.

[27] L. Li, N. Hitchman, J. Knapp, Failure of thermal barrier coatings subjected to CMAS attack, J. Therm. Spray Technol. 19 (2010) 148-155.

[28] J. Wu, H. Guo, Y. Gao, S. Gong, Failure of thermal barrier coatings subjected to CMAS attack, J. Eur. Ceram. Soc. 31 (2011) 1881-1888.

[29] J. Smialek, F. Archer, R. Garlick, Turbine airfoil degradation in the persian gulf war, JOM, 46 (1994) 39-41.

[30] R.G. Wellman, J.R. Nicholls, Erosion, corrosion and erosion-corrosion of EB-PVD 
thermal barrier coatings. Tribol. Int. 41 (2008) 657-662.

[31] R.G. Wellman, G. Whitman, J.R. Nicholls, CMAS corrosion of EB PVD TBCs: Identifying the minimum level to initiate damage. Int. J. Refract. Metal Hard Mater. 28 (2010) 124-132.

[32] I.P. Downs, J.H. Perepezko, R. Sakidja, S.R. Choi, Suppressing CMAS attack with a MoSiB-based coating. Surf. Coat. Technol. 239 (2014) 138-146.

[33] A.R. Krause, B.S. Senturk, H.F. Garces, G. Dwivedi, A.L. Ortiz, S. Sampath, N.P. Padture, 2ZrO2.Y2O3 Thermal Barrier Coatings Resistant to Degradation by Molten CMAS: Part I, Optical Basicity Considerations and Processing. J. Amer. Ceram. Soc. 97 (2014) 3943-3949.

[34] K.I. Lee, L.T. Wu, R.T. Wu, P. Xiao, Mechanisms and mitigation of volcanic ash attack on yttria stablized zirconia thermal barrier coatings. Surf. Coat. Technol. 260 (2014) $68-72$.

[35] M.P. Borom, C.A. Johnson, L.A. Peluso, Role of environment deposits and operating surface temperature in spallation of air plasma sprayed thermal barrier coatings. Surf. Coat. Technol. 86-87 (1996) 116-126.

[36] L.X. Li, T.J. Wang, A unified approach to predict overall properties of composite materials, Mater. Charact. 54 (2005) 49-62.

[37] T. Nakamura, T. Wang, S. Sampath, Determination of properties of graded materials by inverse analysis and instrumented indentation, Acta Mater. 48 (2000) 4293-4306.

[38] J.R. Rice, Mathematical analysis in the mechanics of fracture, J. Appl. Mech. 35 (1968) 379-386.

[39] X. Chen, J.W. Hutchinson, A.G. Evans, Simulation of the high temperature impression of thermal barrier coatings with columnar microstructure, Acta Mater. 52 (2004) 565-571.

[40] X. Chen, R. Wang, N. Yao, A.G. Evans, J.W. Hutchinson, R.W. Bruce, Foreign object damage in a thermal barrier system: mechanisms and simulations, Mater. Sci. Eng. A. 352 (2003) 221-231. 
Table 1. The material parameters used in EB-PVD columnar model [2, 26]

\begin{tabular}{cccccc}
\hline & YSZ Column & CMAS & Gap & Bond-coat & Substrate \\
\hline Young's modulus, E $(\mathrm{GPa})$ & 100 & $5 \sim 120$ & 5 & 200 & 210 \\
Poisson's Ratio, $v$ & 0.25 & 0.25 & 0.25 & 0.3 & 0.3 \\
\hline
\end{tabular}




\section{Figure Captions:}

Fig. 1. Images of EB-PVD thermal barrier coating system: (a) cross section of the system including the ceramic top-coat, bond-coat and the superalloy substrate [16]; and (b) micrograph of the columnar microstructure of ceramic top-coat[18].

Fig. 2. Images of the top-coat delamination in EB-PVD coatingsystem: (a) micrograph of the cross section for a TBCs sample with CMAS penetration, where the top-coat delamination occurs at the interface [25]; (b) slide view of a TBCs sample with the spallation of top-coat after CMAS penetration[23, 26], where some columns are removed completely and the interface exposures to environment; and (c) aschematic of the CMAS induced interfacial delamination, where the delamination emanates from the root of a channel crack or vertical separation.

Fig. 3. A physical model incorporatingthe columnar microstructure of EB-PVD coating, in which the gaps between YSZ columns are partly filled with CMAS deposits.

Fig. 4. Effects of CMAS penetration on the equivalent in-plane and out-of-plane moduli, $E_{1}^{e q}$ and $E_{2}^{e q}$.

Fig. 5. (a) Illustration of interfacial delamination initiating from the root of a channel crack (gap) in a film/substrate system, (b) the two-dimensional plane strain model used to calculate the energy release rate of interfacial crack,and (c) the detailed mesh near the crack-tip. 
Fig. 6. Trends of normalized energy release rate $G / G_{0}$ (a) and mode mixity $\varphi$ (b) with the normalized crack length $a / h_{f}$.

Fig. 7. Variations of normalized energy release rate (a) and mode mixity (b) with the in-plane modulus of film $E_{1}^{f}$.

Fig. 8. Variations of normalized energy release rate (a) and mode mixity (b) with the out-of-plane modulus of film $E_{2}^{f}$.

Fig. 9. Effects of substrate properties (in-plane modulus $E_{1}^{s}$ and out-of-plane modulus $E_{2}^{s}$ ) on the normalized energy release rate (a) and mode mixity (b).

Fig. 10. Effects of CMAS modulus on the normalized energy release rate in the columnar model, where $G_{*}$ is the energy release rate for the case of $h_{C M A S}=h_{Y S Z}$, $E_{C M A S}=E_{Y S Z}$ (isotropic) and $a=50(d+D)$. The results obtained by the continuum analysis are also presented, in which the YSZ top-coat is treated as a transversely isotropic material and the equivalent moduliare predicted by Eqs. (1) and (2) using the microstructure parameters of columnar model.

Fig. 11. Relative change of energy release rate, $\delta$, under three different column widths, where $\delta$ is defined by $\delta=\left|G_{c o l}-G_{e q}\right| / G_{c o l} \times 100 \% . G_{c o l}$ and $G_{e q}$ are the energy release rate predicted by columnar model and continuum analysis, respectively.

Fig. 12. Combined effects of CMAS modulus and penetration thickness on the energy release rate of interfacial delamination in the columnar model. 
Fig. 13. Effects of CMAS modulus on the mode mixityinthe columnar model, where the results for four different penetration thicknesses are plotted.

Fig. A1. The columnar ceramic top-coat partly filled with CMAS penetration, which is divided into two parts: part (A) with CMAS and part (B) without CMAS. 
Click here to download high resolution image
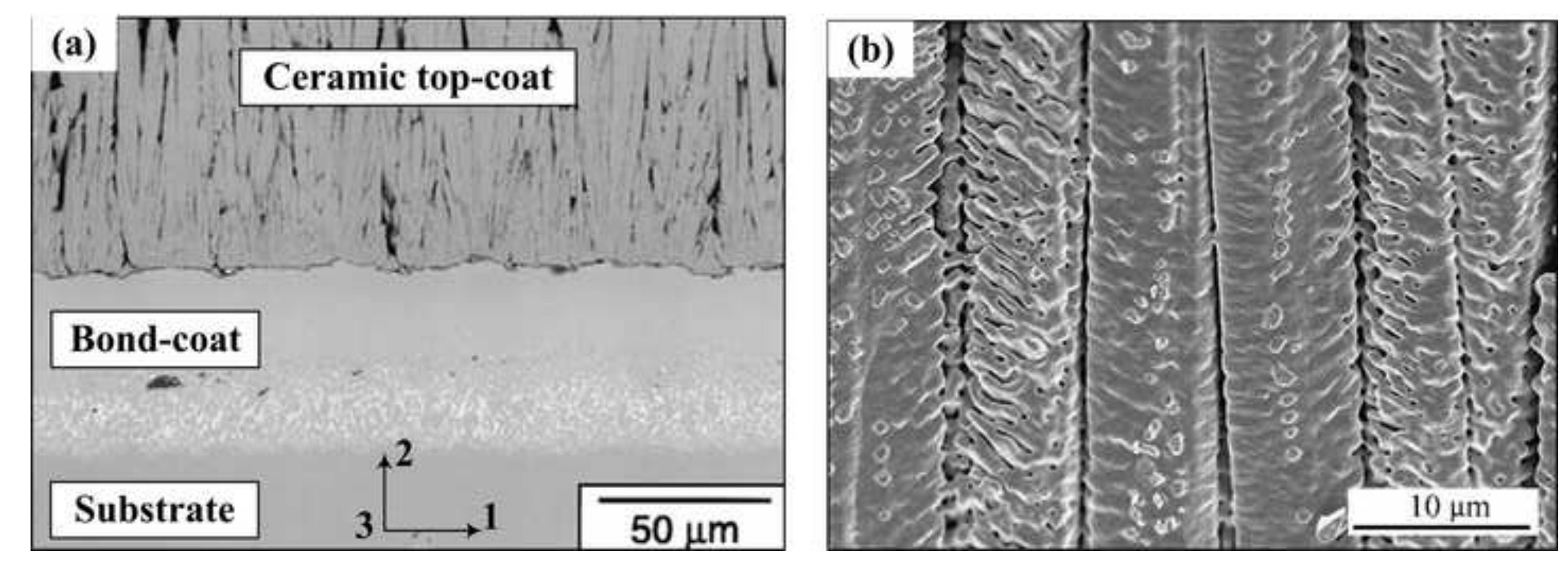


\section{Figure 2}

Click here to download high resolution image
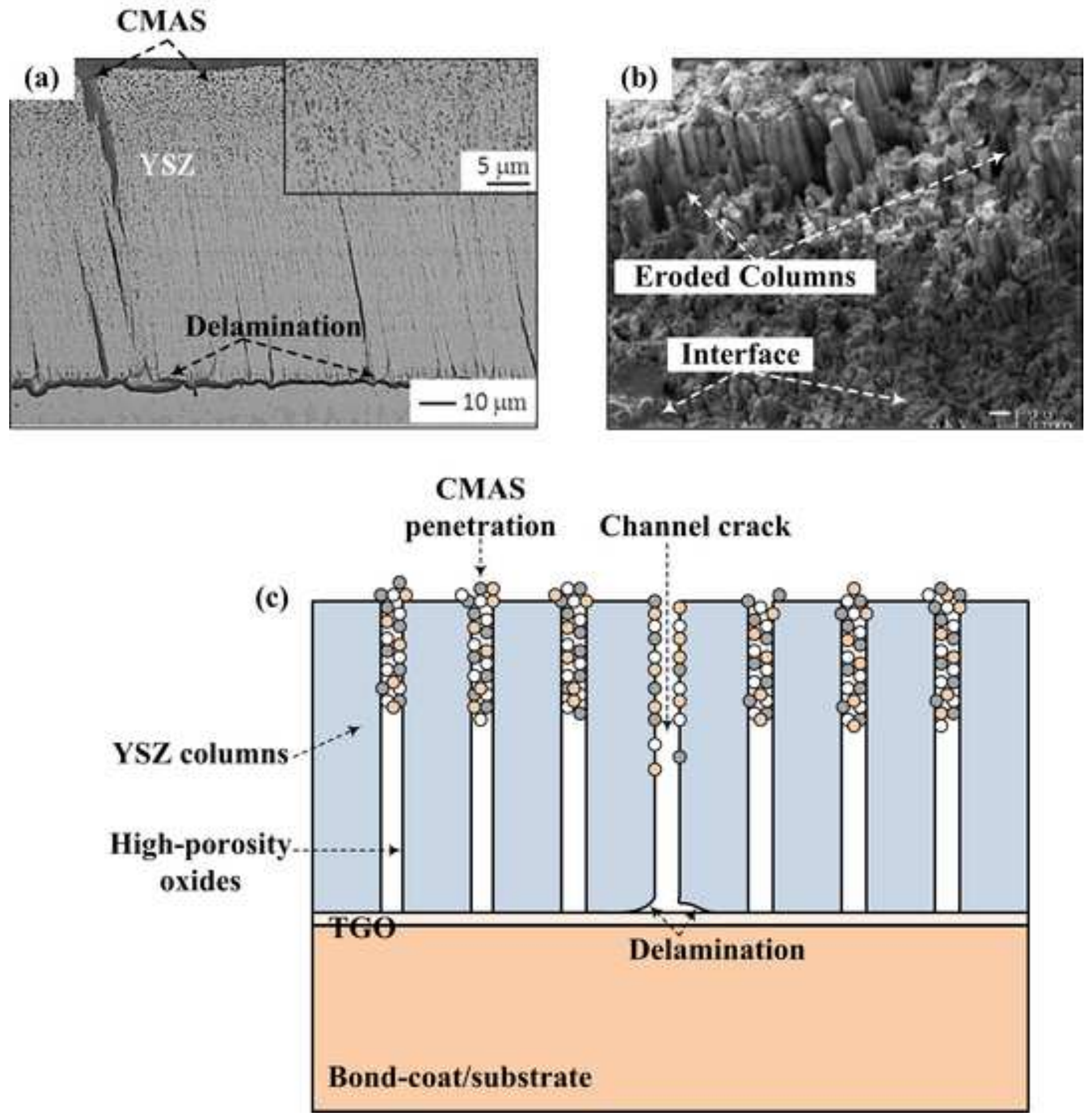


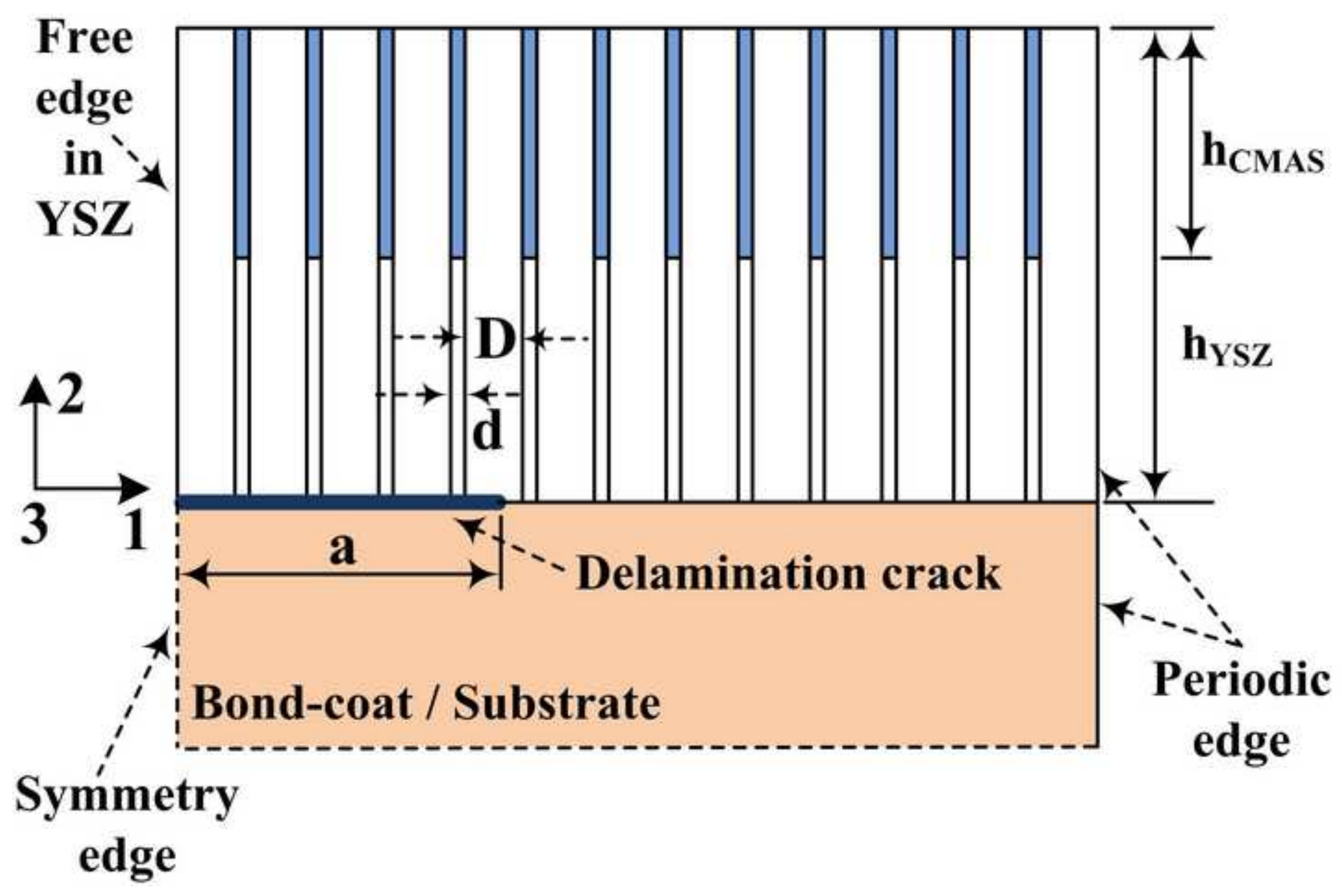




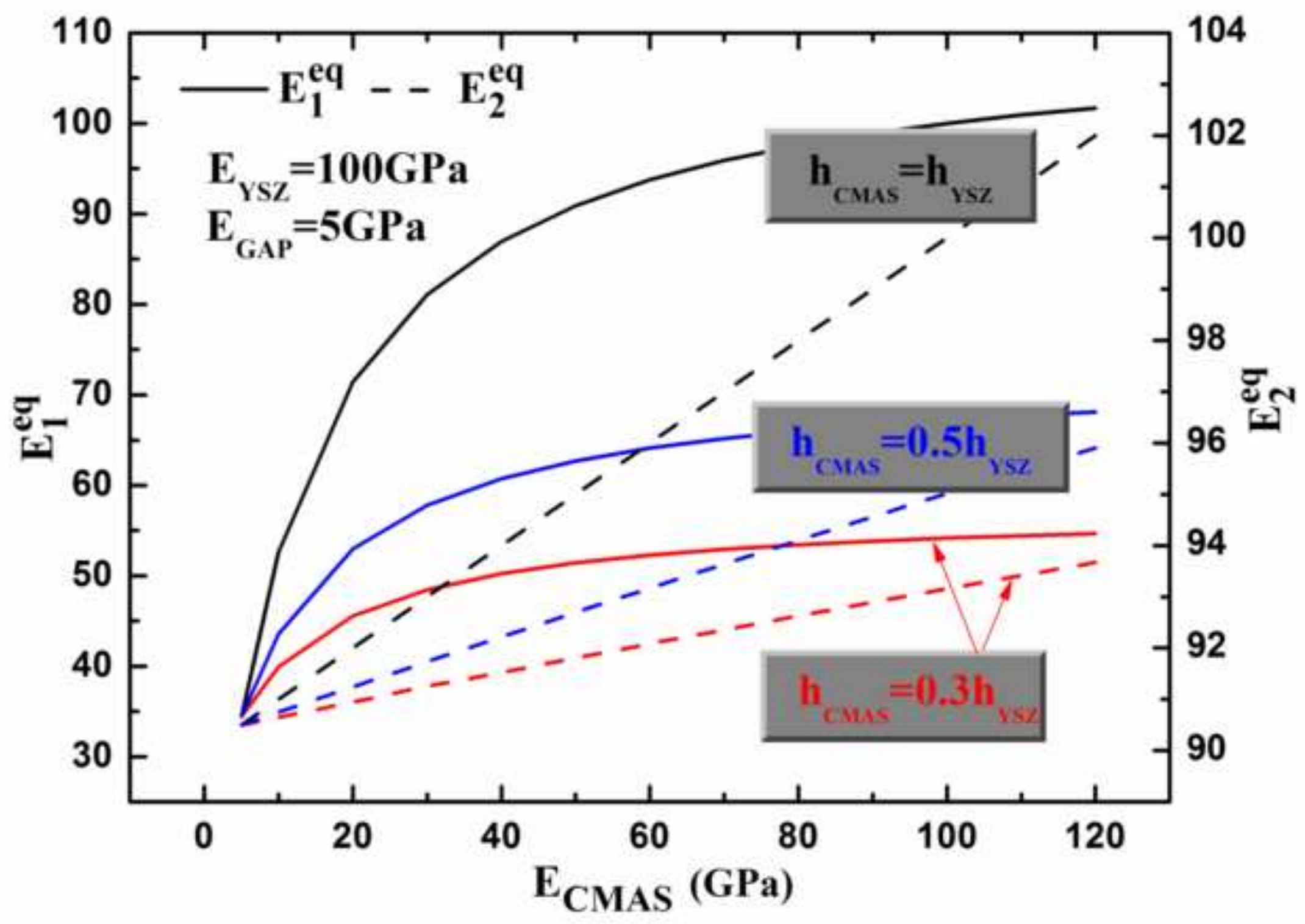


(a)

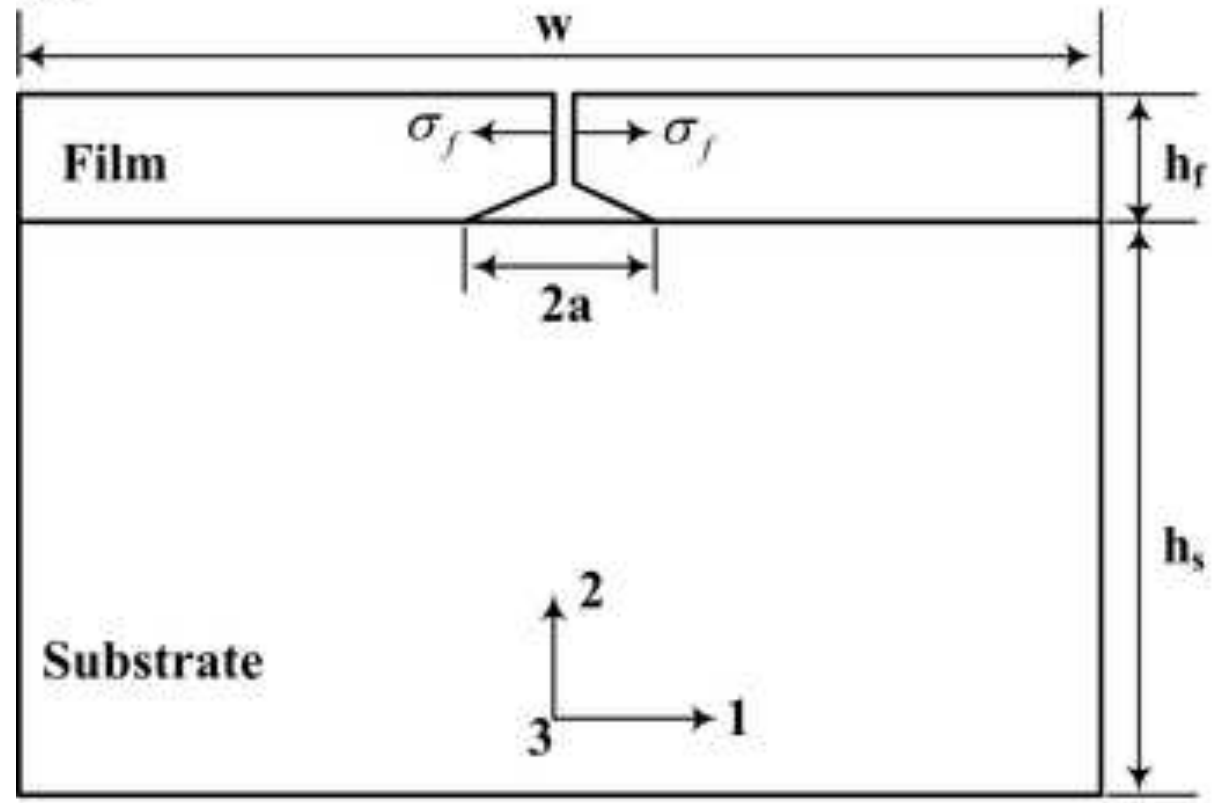

(b)

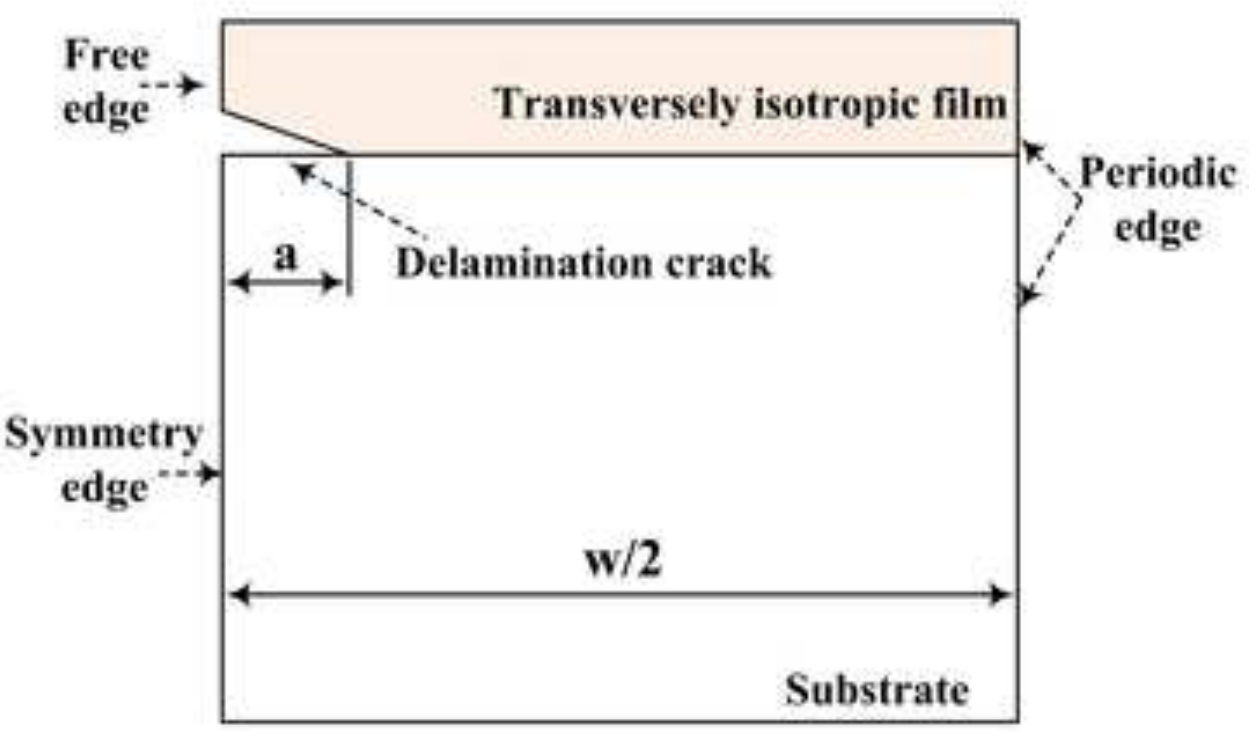

(c)

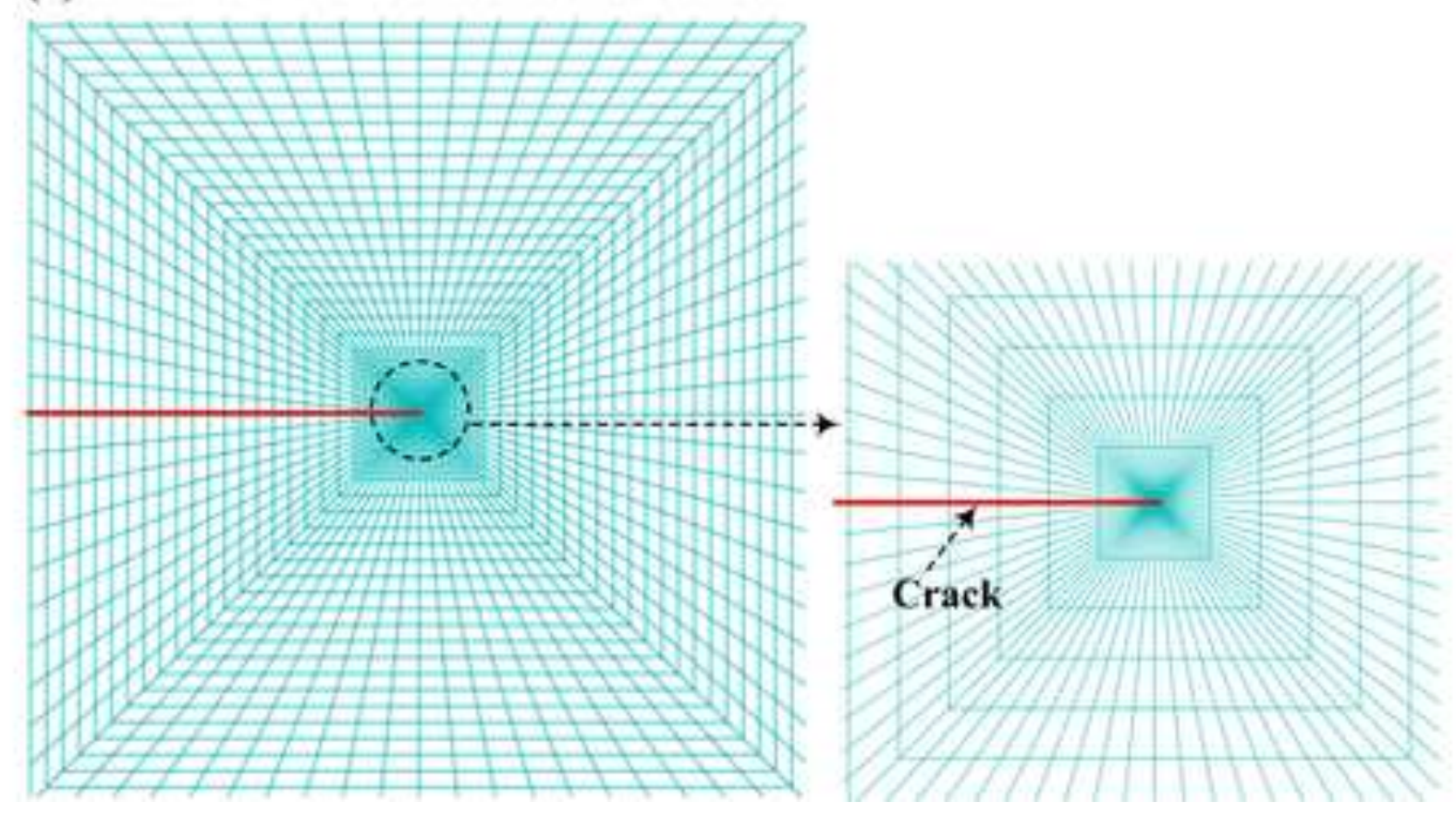



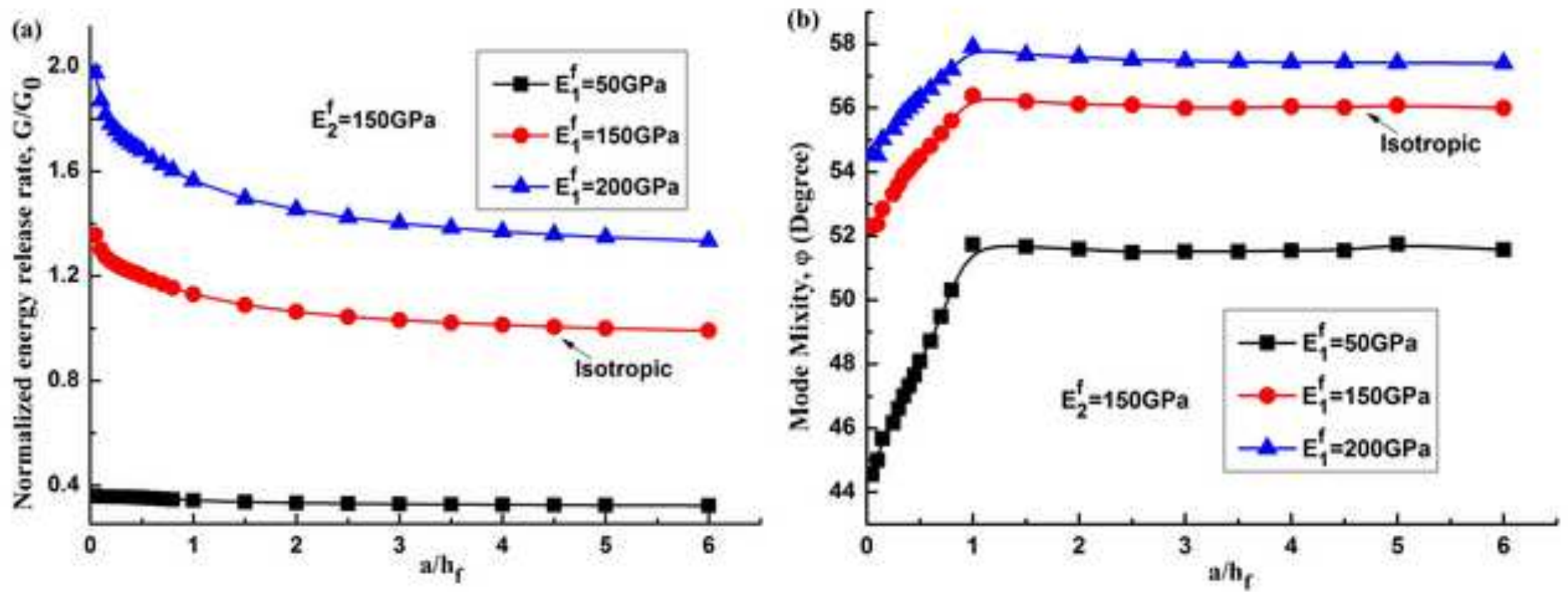

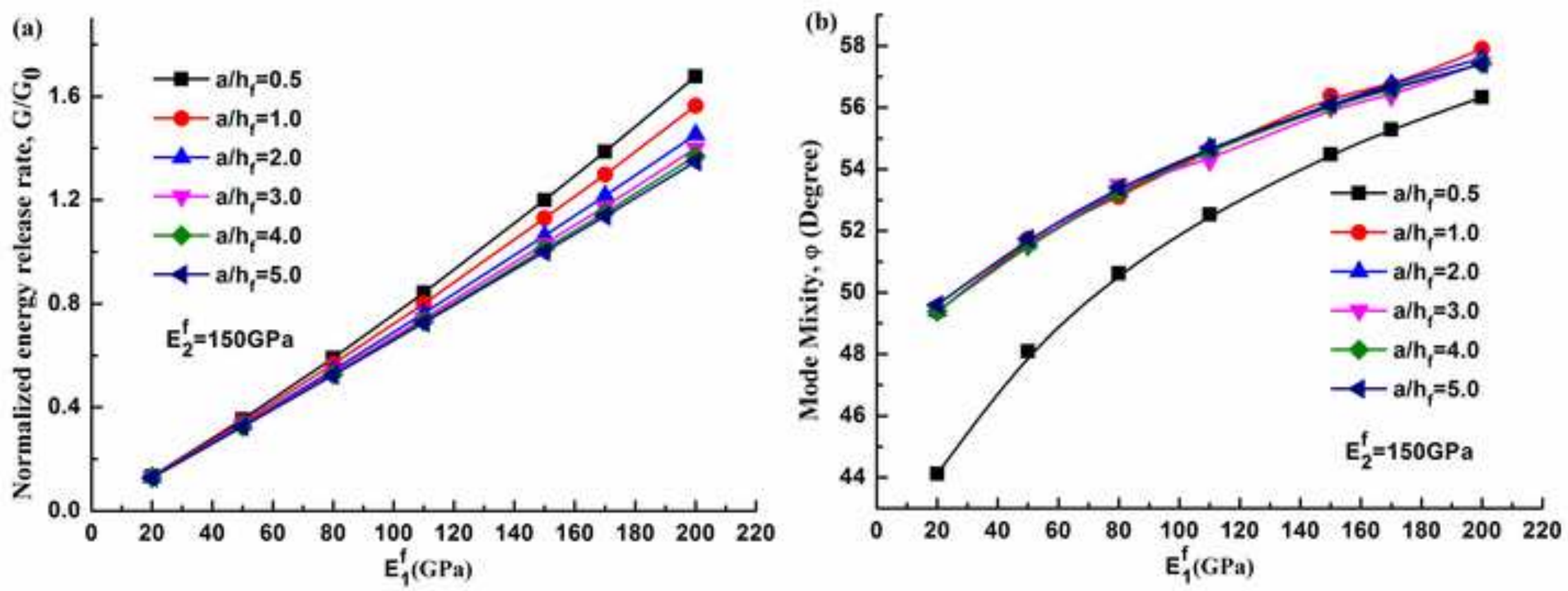

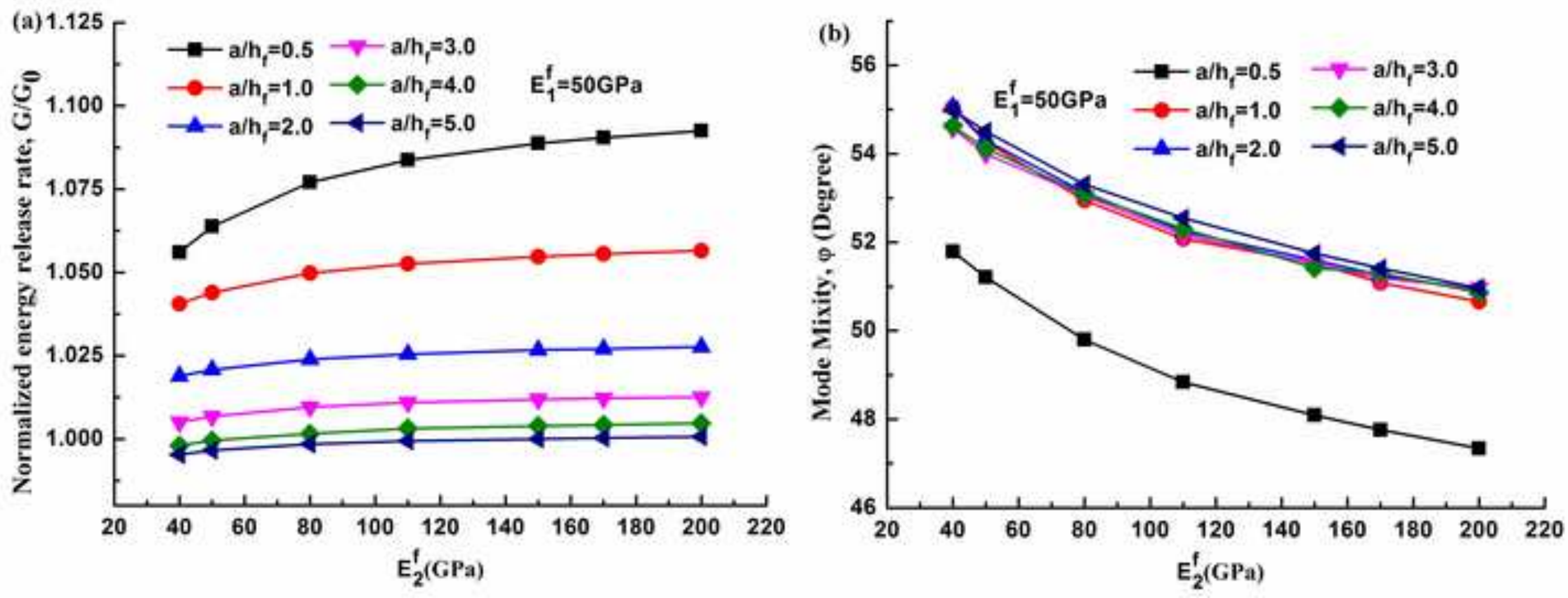

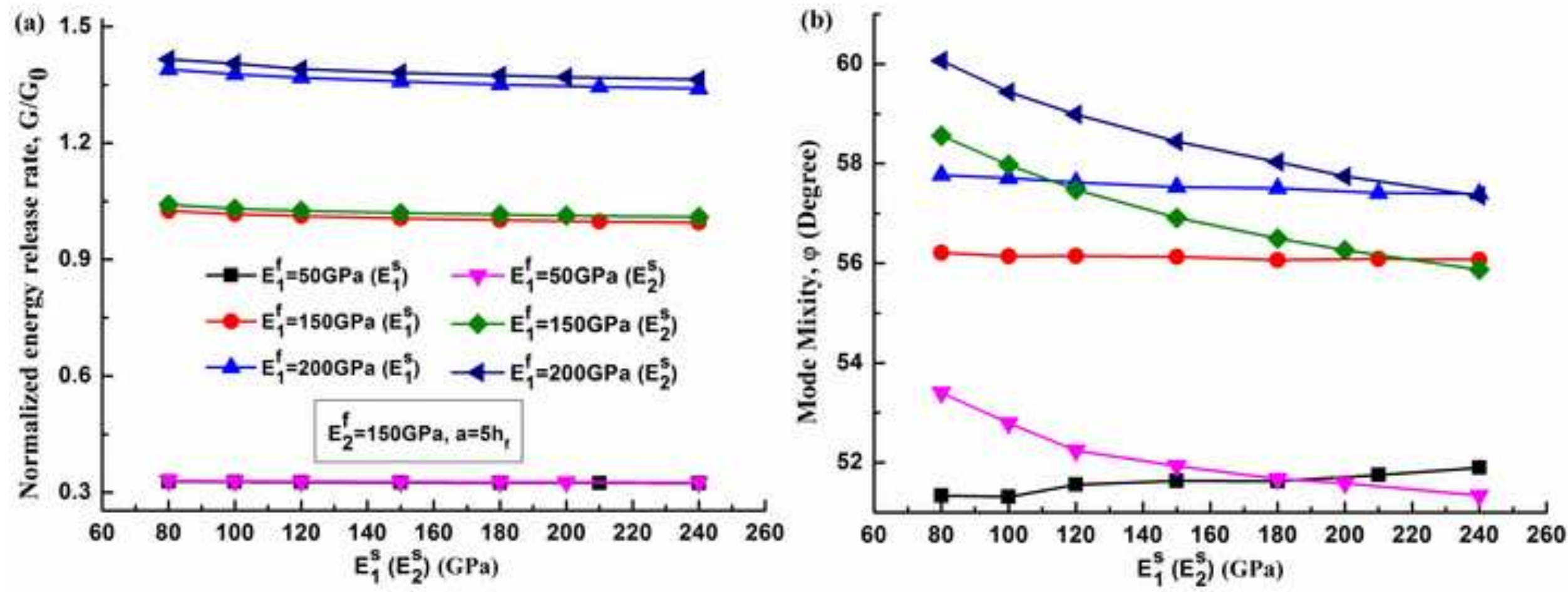


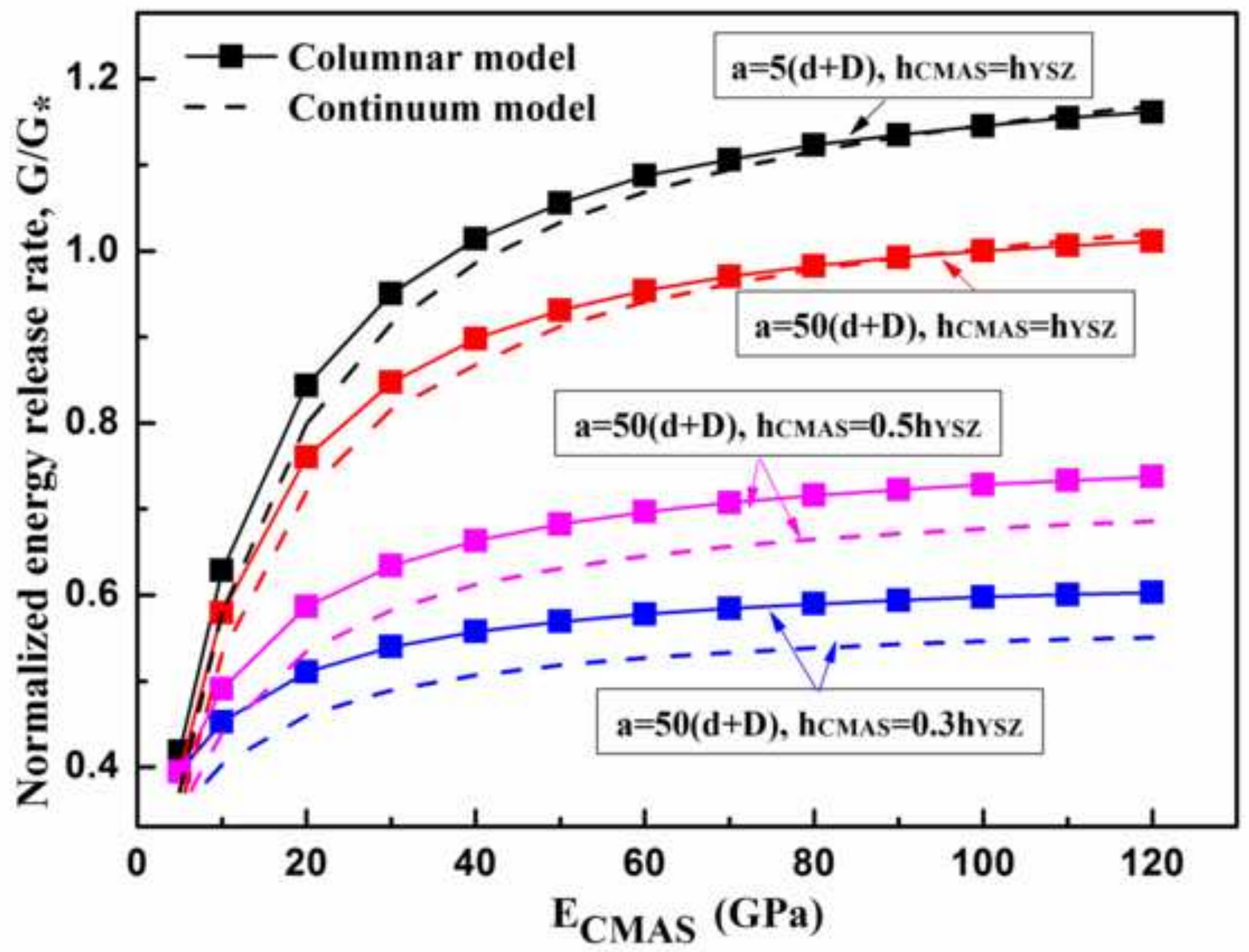




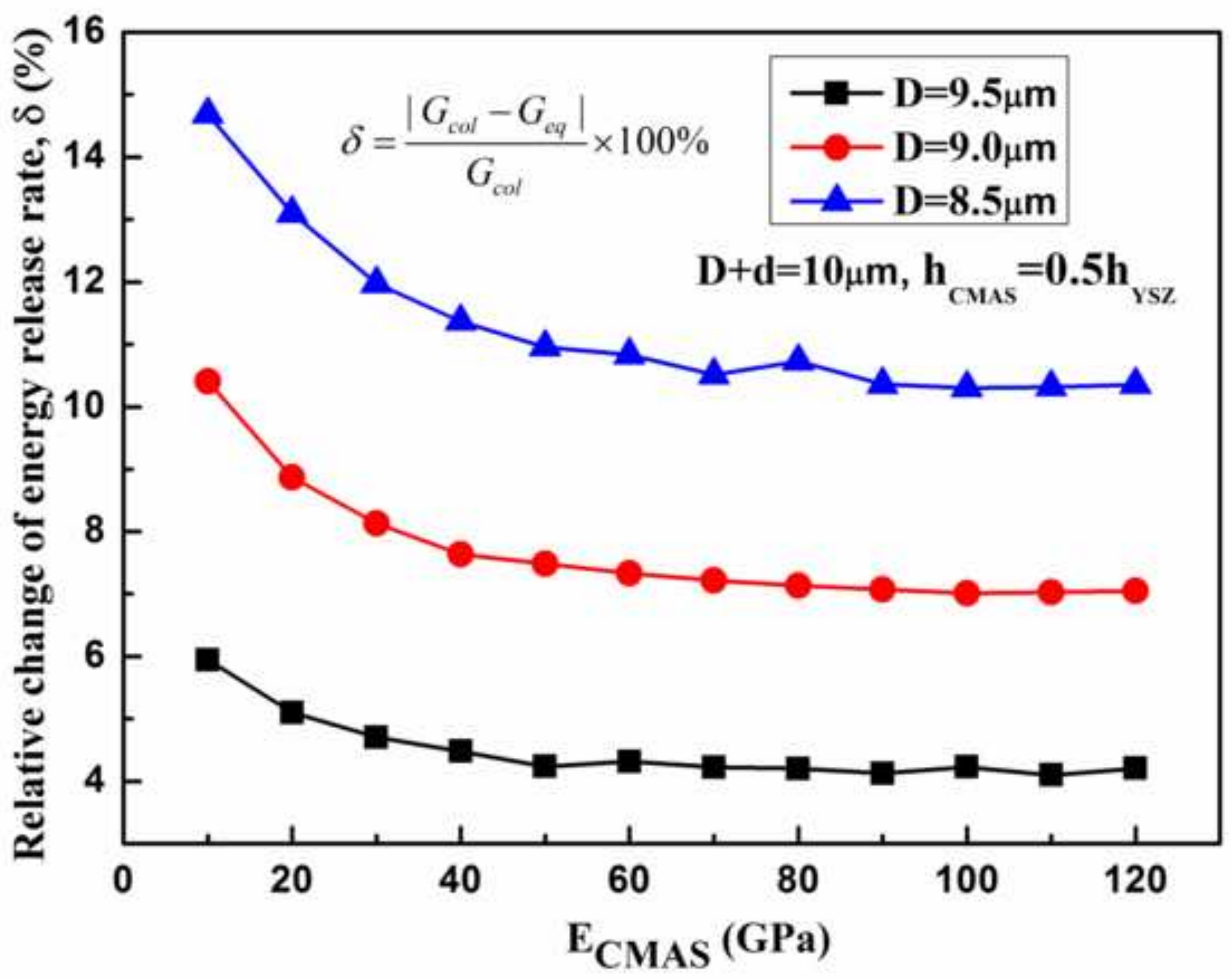




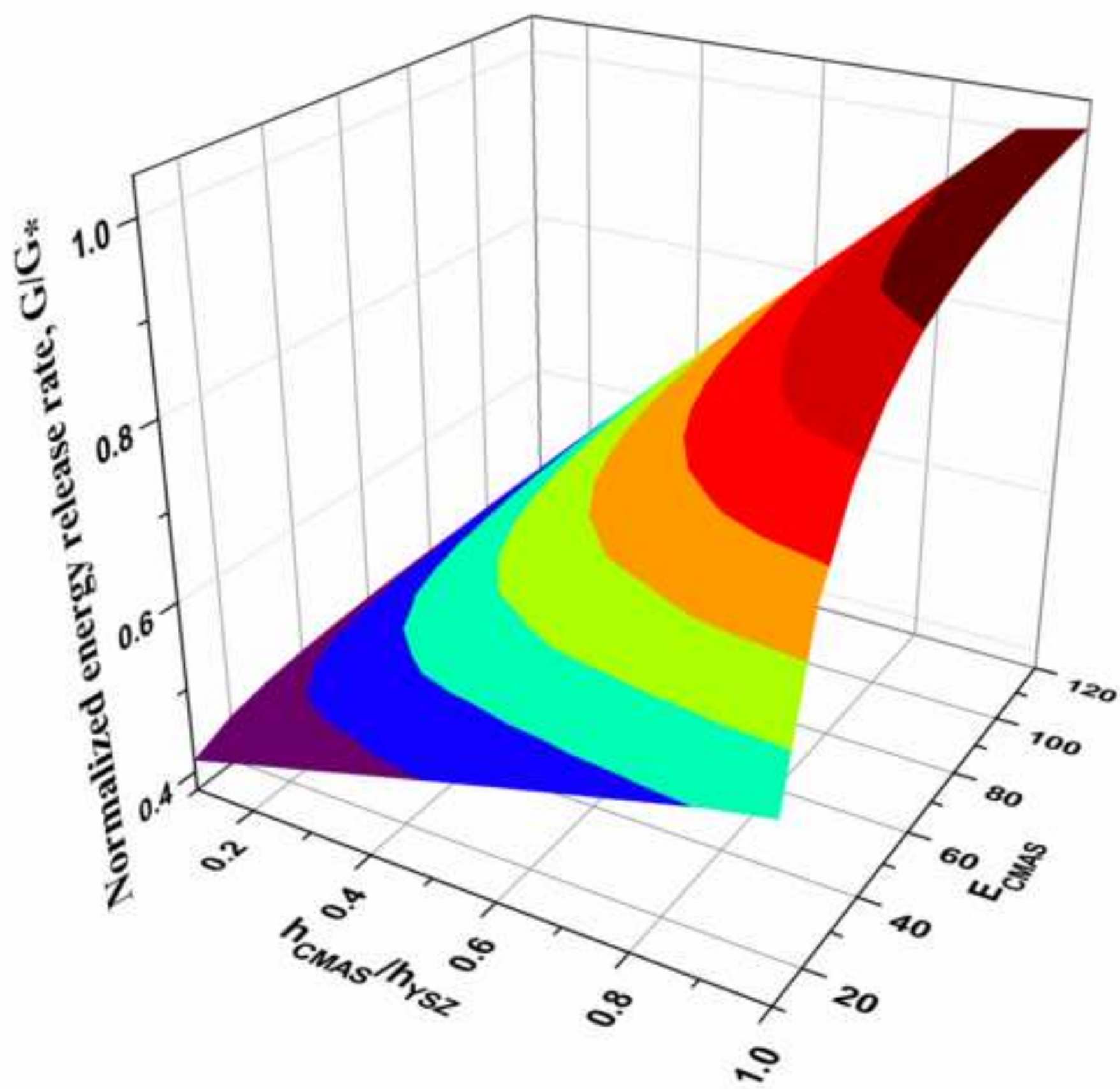




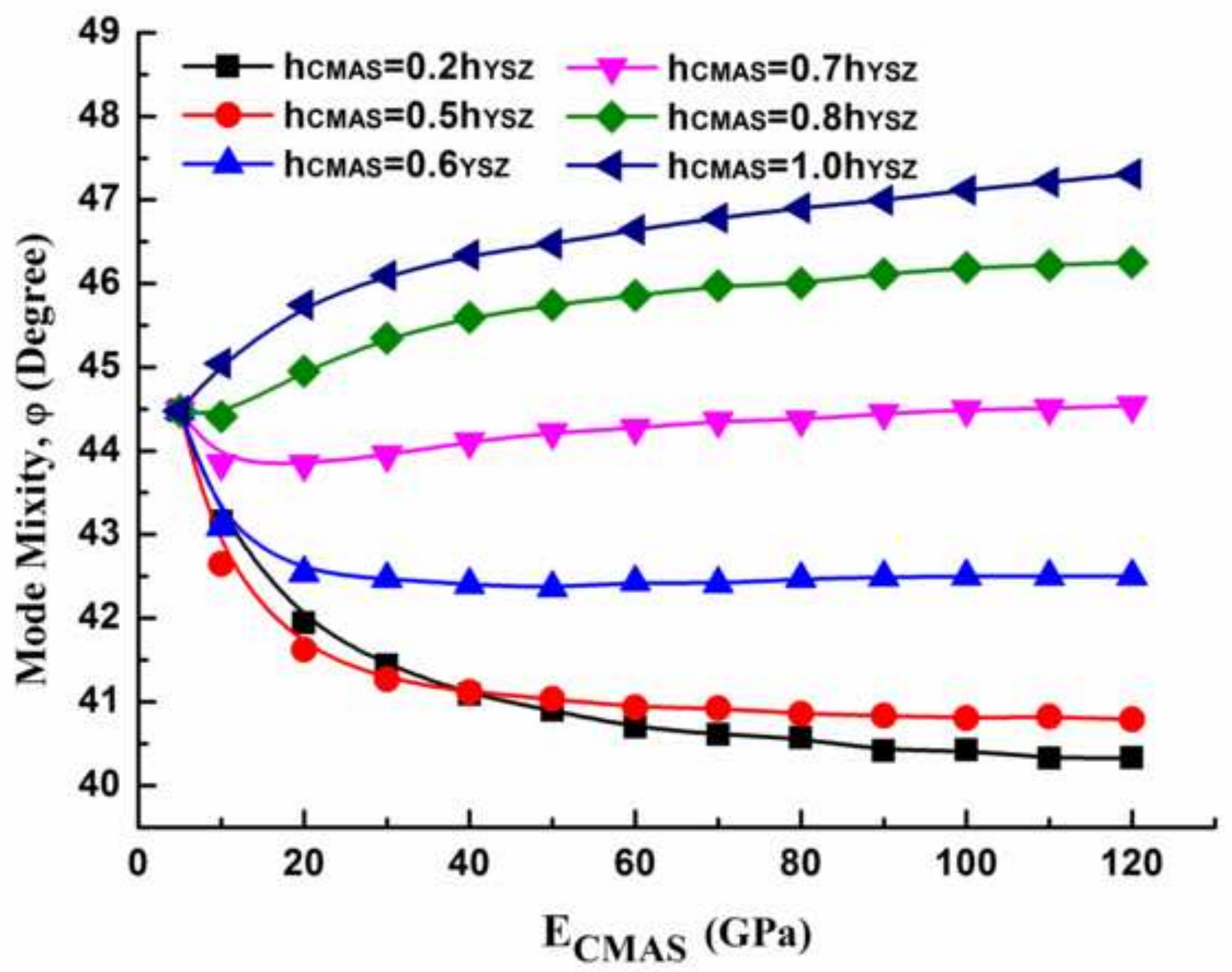




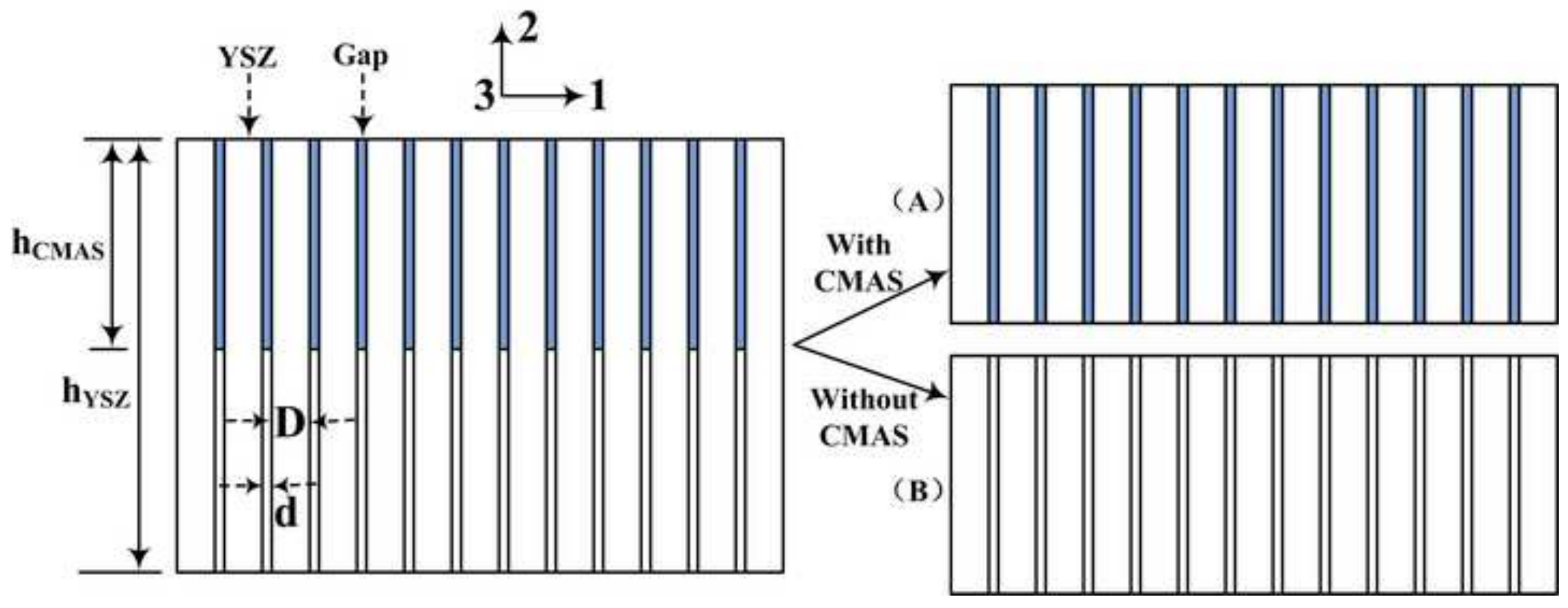

